International Asset Market, Nonconvergence, and Endogenous Fluctuations

Tomoo Kikuchi

September 2006

Discussion Paper No. 556

Department of Economics

Bielefeld University

P.O.Box 100131

D-33501 Bielefeld

Germany 


\title{
International Asset Market, Nonconvergence, And Endogenous Fluctuations *
}

\author{
Tomoo Kikuchi ${ }^{\dagger}$
}

September 2006

Discussion Paper No. 556

\begin{abstract}
We develop an overlapping generations model with retradeable paper assets and capital accumulation to analyze the interaction between the real economy and an international asset market. The world consists of two homogeneous countries, which differ only in their initial levels of capital. Two period lived consumers transfer wealth over time and across countries by holding international mutual funds which pay stochastic dividends. The optimal portfolio decisions of consumers do not necessarily induce convergence of incomes between the two countries. Moreover, interaction through the asset market induces endogenous fluctuation of capital flows between the rich and the poor country.
\end{abstract}

Keywords: international asset market, endogenous cycles, inequality of nations, two-country model JEL classification: E44, F43, O11

\footnotetext{
*I acknowledge the financial support of the Germany Research Foundation Bo. 635/12-1. I thank Volker Böhm, Marten Hillebrand, Olaf Schmitz, and George Vachadze for helpful discussions and suggestions, seminar participants at Bielefeld University, and participants of the Vigoni Workshop in Milano, December 2005, the DEGIT-XI in Jerusalem, June 2006, and the Australasian Meeting of the Econometric Society in Alice Springs, July 2006 for helpful comments.

${ }^{\dagger}$ Bielefeld University, Department of Economics, P.O.Box 100131, D-33501 Bielefeld, Germany; tkikuchi@wiwi.uni-bielefeld.de
} 


\section{Introduction}

How does the integration of financial markets affect the capital accumulation of countries? The conventional wisdom suggests that international financial markets allocate the savings of the integrated economies to its most profitable use. Suppose that the world consists of identical countries which differ only in their levels of initial capital. The standard neoclassical technology implies capital flows from rich countries to poor countries so long until the rate of return in all countries is equalized. In fact, a perfect international capital market implies an immediate adjustment of per capita income across countries. However, as Lucas put it "Why doesn't capital flow from rich to poor countries?" (see Lucas 1990). In the paper he discusses why capital does not flow from rich to poor countries to the extent which a standard neoclassical model would predict. Responding to Lucas' paradox, the neoclassical growth models have been revised to include mainly aspects of heterogeneity, human capital, income distribution and capital market imperfections (for a survey see Galor (1996)). These extended models show that the neoclassical framework with constant return to scale and diminishing marginal product is consistent with club convergence. In other words their economic system can be characterized by multiple, locally stable steady states. However, most of these models are closed economy models without an explicitly modelled international financial market. Notable exceptions are the one sector overlapping generations models modified to incorporate capital market imperfections by Boyd \& Smith (1997) and Matsuyama (2004). ${ }^{1}$ In both models the world economy consists of inherently identical countries, which differ only in their levels of capital. It is the wealth dependent borrowing constraint in Matsuyama (2004) and the external financing associated with a costly state verification problem in Boyd \& Smith (1997) that counteract the equalizing force of the diminishing marginal productivity. Both models show that symmetry breaking occurs in the presence of the international financial market. That is, the symmetric steady state loses its stability and stable asymmetric steady states come to exist.

Matsuyama (2004) and Boyd \& Smith (1997) analyze models in which there are no risks associated with economic activities. It has been a tradition in economic theory to conduct separate analysis of the activities of the real and financial sectors of the

\footnotetext{
${ }^{1}$ It is well known that in the one sector overlapping generations model multiple steady states could emerge if the wage function is not a concave function of capital labor ratio. They do not rely on this result.
} 
economy. However, when financial markets are incomplete, the two sectors cannot be treated independently. Production and consumption decisions depend on the risk sharing possibilities offered by the financial sector, while agents' financial decisions in turn depend on the consumption needs and investment opportunities created by the real sector. Therefore, the framework in Matsuyama (2004) and Boyd \& Smith (1997) ignores two important aspects. Firstly, it prevents us from studying the nature of a wide array of assets, which are subject to uncertainty. Secondly, it obscures the role of asset trade in reaction to unexpected events.

The role of financial markets in an uncertain world is well established in the literature. The theory of general equilibrium with incomplete markets suggests how to overcome the effects of uncertainty and how to allocate the risk optimally. How does international trading of assets influence capital accumulation of countries in an uncertain world? There are few models which provide us with an answer to this question. Acemoglu \& Zilibotti (1997) augment the neoclassical growth model with the assumption that investment in risky projects is indivisible. They show that risk averse agents avoid risky investment which slows down capital accumulation. In addition, the inability to diversify idiosyncratic risk initially introduces a large amount of uncertainty in the growth process. The more the economy accumulates capital, the better it diversifies risk. Eventually, it converges to its steady state, in which all investment sectors are open and risk is completely diversified. Thus, they offer a theory of development that links the degree of market incompleteness to capital accumulation. Their results generalize to economies with international capital flows. Obstfeld (1994) extends the endogenous growth model by Romer (1990) and shows in a continuous time stochastic model that the possibility of world portfolio diversification can raise steady state growth, as individuals place a larger fraction of their wealth in risky but high-yielding capital investments.

There are two main aspects which characterize the literature. Firstly, the financial intermediary facilitates the trading of risk thereby allowing individuals to engage in risky activities that yield higher return at the aggregate level. Thus, higher risk is assumed to be associated with not just higher return but also with higher productivity in the real sector. Therefore, the efficiency in the financial market is linked to the productivity in the real sector. Secondly, it is assumed that the activities in the real sector go hand in hand with the activities in the financial sector. In other words, capital accumulation is associated with an increase in the volume of intermediation. Therefore, financial activities grow as a proportion of gross domestic product. Goldsmith (1969) 
provides empirical evidence for this argument.

However, the development of financial markets today is typically accompanied by a disproportionate increase in the trade volume of financial capital and not of real capital. For example, firms can raise capital by issuing new shares in stock markets. However, it is known that a large part of financial trading in the stock markets is trading of existing shares in the markets. Therefore, transactions in financial markets need not be related to productivity in the real sector. So what is it that creates the deviation we observe between the trade volume between financial capital and real capital? Typically, trading of existing shares is influenced by price expectations, which may be influenced by various factors. To analyze the nature of such a financial market and its implication on capital accumulation we have to develop a model in which an asset price process and an endogenous income process are integrated.

There are a number of works, which embed the analysis of income flows on financial markets into a structure of real markets. Donaldson \& Mehra (1984) were the first to provide the link between asset prices, the profit maximizing firms, and utility maximizing representative agents in a general equilibrium model. They analyzed the quantitative effects of how underlying preferences and technologies are related to asset prices. Huffman (1986) employed a two period overlapping generations model, which allows for heterogenous participation in the asset market. However, the underlying economy is modelled as an exogenous process leaving the question of general equilibrium out of the analysis. Donaldson \& Mehra (1984) and Huffman (1986) derive the asset price from the stochastic intertemporal Euler equation, while the dividend is defined as the difference between the value of capital before and after production. Thus, the asset price and the dividend are intimately related to real capital reflecting the fundamentals of the firm. The asset price is interpreted as a shadow price which supports the intertemporal consumption decision and therefore trading does not actually take place in the financial market.

The present paper modifies the standard overlapping generations model with two period life time in two ways. Firstly, it introduces additive shocks to production. Secondly, it introduces an additional commodity, a nominal asset, that can be traded amoung agents to transfer their wealth over time. The asset market is modelled as in Böhm \& Chiarella (2005) in which asset prices are determined endogenously by the interaction of utility maximizing agents. Since agents consume only in the second period, a young agent's objective is to choose a portfolio of assets and capital investment to maximize the utility 
of the next period consumption. The model by Böhm \& Chiarella (2005) is extended so that the income stream is endogenous and the factor prices are determined by their respective marginal products. The return of the capital investment is the marginal product of capital, while the price of the assets is not linked to production. We abstract from the issuing of new shares. The firm pays out the random profit as dividends to shareholders. The asset price is determined by the trading of the existing shares between young and old agents in the market. This allows us to examine the interplay between the capital investment and the trading of existing shares.

The role of a nominal asset, which can be traded in an uncertain world can be twofold in an overlapping generations model. Firstly, it can be used by the firm to transfer the random part of the production to the consumption of the old. This shift of the randomness between generations induces a deterministic law of capital accumulation, making the consumption of the old the only stochastic variable. Secondly, young consumers can hold the asset to transfer wealth to the next period. This serves to smooth their consumption plan given their preferences. The present paper extends the analysis of the role of the nominal asset to a two country framework. The world consists of two homogeneous countries, which differ only in their initial levels of capital. International mutual funds are introduced where stochastic profits of firms in both countries constitute the dividends. Since young agents in both countries have different incomes in general, short selling is possible in the international asset market. This means that the poor country takes credits by the short selling of assets, which induces trade of assets between generations as well as across countries. International asset market brings about convergence of incomes between the two countries only if the risk adjusted dividend is negative and the initial conditions of the two countries are sufficiently high. If the risk adjusted dividend is positive and the initial condition of one country is sufficiently low while that of the other is sufficiently high, the two country diverge in the long run.

Furthermore, endogenous fluctuation of international capital flows between the rich and the poor country occur in the long run. The closed economy model does not exhibit any fluctuations. This suggests that interactions in the international asset market generate endogenous fluctuations of international capital flows. Boyd \& Smith (1997) motivate their paper by referring to cyclicality of credit allocation between developing and developed economies in empirical data. However, their theoretical findings are confined to a dynamical equilibrium path displaying damped oscillation. Perfect foresight models are often abandoned and real business cycles (RBC) models are adopted to integrate short 
term fluctuation into long rung growth analysis. The present model shows that it is a misconception that perfect foresight models can not explain short-term fluctuations. Fluctuations in RBC models are interpreted as propagation mechanism of exogenous shocks. This difference has different theoretical as well as political implications. While RBC models understand fluctuation as an adjustment process to a steady state, the present two country model suggests that fluctuations may be inherent in the structure of the international financial market.

The remainder of the paper is organized as follows. Section 2 introduces the basic structure of the model. Section 3 defines the temporary equilibrium of the closed economy and Section 4 analyzes its dynamics. Section 5 then extends the closed economy model to a two country model. Section 6 analyzes the steady state properties of the two country model and compares the results with those from the closed economy model. Section 7 concludes.

\section{The Model Structure}

We consider an overlapping generations economy evolving in discrete time. In addition to the markets for output, labor, and capital, there is a market for paper assets which can be retraded. Purchase of the re-tradable paper assets is distinguished from investment in capital in two ways. Firstly, paper assets are not linked to production. Secondly, while capital is reproduced every period, the number of assets is exogenously given in the model. Each generation consisting of homogeneous consumers lives for two periods and we assume that there is no population growth. All markets operate under perfect competition implying that agents are price takers.

\subsection{The Production Sector}

There is a single firm, which lives infinitely long in the economy and uses one unit of labor $L$ and capital $K$ to produce consumption goods. The aggregate production function is given by

$$
F(K, 1)+\varepsilon,
$$

where $F$ is homogeneous of degree one, $\varepsilon$ is an additive shock to production. Then the intensive form can be written as

$$
f(k)+\varepsilon
$$


where $k:=\frac{K}{L}$. The labor and capital markets are assumed to be competitive such that the profit maximizing firm pays the wage $w(k):=f(k)-k f^{\prime}(k)$ and the return on capital investment $r(k):=f^{\prime}(k)$ according to the marginal product rule. The stochastic output is paid to shareholders as a dividend per share. In the overlapping generations structure the young agents are the shareholders of the firm and receives the dividend payment when they are old. This time structure is particulary important since the source of the randomness is completely absorbed by the asset market. The firm transfers the random component of production to the consumption of the old thereby leaving all the other variables deterministic.

Assumption 1 The production function in intensive form $f: \mathbb{R}_{+} \rightarrow \mathbb{R}_{+}$is $C^{2}$ and $f^{\prime \prime}(k)<0<f^{\prime}(k)$ and satisfies the Inada conditions $\lim _{k \rightarrow \infty} f^{\prime}(k)=0$ and $\lim _{k \rightarrow 0} f^{\prime}(k)=$ $\infty$ for $k>0$.

\subsection{The Consumption Sector}

The typical young consumer in period $t=0$ supplies one unit of labor inelastically in the first period of his life time and receives labor income $w$ in units of consumption good which is the numéraire good. ${ }^{2}$ His lifetime utility depends on old age consumption only. There is no storage possibility for the consumption goods. He can transfer his wage income to the next period either by investing in capital or by purchasing assets. The young agent cannot take credit in the capital market. In the second period of his life time when he is old, the agent receives the rate of return $R_{1}$ on his capital investment $y$ and a random dividend $\varepsilon_{1}$ on his share holdings $x$, which he resells in the market. The following assumptions characterize the consumers.

Assumption 2 Consumers have risk preferences over the mean $\mu$ and the standard deviation $\sigma$ of future consumption/wealth described by a utility function

$$
U:\left\{\begin{array}{l}
\mathbb{R}_{+} \times \mathbb{R}_{+} \rightarrow \mathbb{R} \\
(\mu, \sigma) \mapsto U(\mu, \sigma)
\end{array}\right.
$$

which is increasing in the mean $\mu$ and decreasing in the standard deviation $\sigma$.

\footnotetext{
${ }^{2}$ For ease of notation the time index $t$ will be suppressed unless necessary. Variables without time subscript refer to an arbitrary period $t$ while subscript 1 refers to period $t+1$ and -1 to period $t-1$.
} 
Let $(x, y) \in \mathbb{R} \times \mathbb{R}_{+}$denote a portfolio of assets and capital investment and let $p \in \mathbb{R}_{+}$ denote the current price of risky assets in units of the consumption commodity. The budget constraint takes the form

$$
w=p x+y .
$$

Then, the investor's wealth in the following period $t=1$ is given by

$$
W\left(w, p, x, R_{1}, p_{1}, \varepsilon_{1}\right)=R_{1}(w-p x)+\left(p_{1}+\varepsilon_{1}\right) x .
$$

When making the portfolio decision, the next period's return on capital, equity price, and dividend $\left(R_{1}, p_{1}, \varepsilon_{1}\right)$ are uncertain for young agents. It is assumed that they make point forecasts $\left(R^{e}, p^{e}\right)$ for the return on capital and the asset price. Notice that we separate the expectations for the asset price from the expectations for the dividend payment, which is the only source of randomness. The following assumption is made about the expectation for the next period's dividend payment $\varepsilon_{1}$.

Assumption 3 Consumers are endowed with a subjective probability distribution $\nu \in$ $P\left(\mathbb{R}_{+}\right)$for the next period's dividend payment parameterized by a pair $\left(\mathbb{E}_{\nu}[\varepsilon], \mathbb{V}_{\nu}[\varepsilon]\right) \in$ $\mathbb{R}_{+} \times \mathbb{R}_{++}$of expected value and variance.

Then, for any asset portfolio $x \in \mathbb{R}$ the subjectively expected value of the future wealth can be expressed as

$$
\begin{aligned}
\mathbb{E}_{\nu}\left[W\left(w, p, x, R^{e}, p^{e}, \cdot\right)\right] & =\int_{\mathbb{R}_{+}}\left(R^{e} w+\left(p^{e}+\varepsilon-R^{e} p\right) x\right) \nu(d \varepsilon) \\
& =R^{e} w+\left(p^{e}+\mathbb{E}_{\nu}[\varepsilon]-R^{e} p\right) x
\end{aligned}
$$

with associated subjective variance

$$
\begin{aligned}
\mathbb{V}_{\nu}\left[W\left(w, p, x, R^{e}, p^{e}, \cdot\right)\right] & =\int_{\mathbb{R}_{+}}\left(W\left(w, p, x, R^{e}, p^{e}, \varepsilon\right)-\mathbb{E}_{\nu}\left(W\left(w, p, x, R^{e}, p^{e}, \cdot\right)\right)\right)^{2} \nu(d \varepsilon) \\
& =x^{2} \mathbb{V}_{\nu}[\varepsilon]
\end{aligned}
$$

where $p^{e}+\mathbb{E}_{\nu}[\varepsilon]-R^{e} p$ is the expected risk premium. The young agent's objective is to maximize the utility of next period consumption defined by

$$
\max _{x \in \mathbb{R}}\left\{U\left(\mathbb{E}_{\nu}\left[W\left(w, p, x, R^{e}, p^{e}, \cdot\right)\right], \mathbb{V}_{\nu}\left[W\left(w, p, x, R^{e}, p^{e}, \cdot\right)\right]^{\frac{1}{2}}\right) \mid x \leq \frac{w}{p}\right\}
$$

which by equations (1) and (2) is identical to

$$
\max _{x \in \mathbb{R}}\left\{U\left(R^{e} w+\left(p^{e}+\mathbb{E}_{\nu}[\varepsilon]-R^{e} p\right) x, x \sqrt{\mathbb{V}_{\nu}[\varepsilon]}\right) \mid x \leq \frac{w}{p}\right\} .
$$


The following assumption characterizes the rational expectations of young consumers. ${ }^{3}$

Assumption $4\left\{\varepsilon_{t}\right\}_{t \geq 0}$ is an i.i.d sequence of random variables with finite first and second moments. We assume that the agents have correct knowledge of these moments such that

$$
\mathbb{E}_{\nu}\left[\varepsilon_{t}\right]=\mathbb{E}\left[\varepsilon_{t}\right]
$$

where $\mathbb{E}\left[\varepsilon_{t}\right]$ is the mean value of the random variable $\varepsilon_{t}$ and

$$
\mathbb{V}_{\nu}\left[\varepsilon_{t}\right]=\mathbb{V}\left[\varepsilon_{t}\right]
$$

where $\mathbb{V}\left[\varepsilon_{t}\right]$ is the variance of the random variable $\varepsilon_{t}$.

\section{The Closed Economy Model}

We assume that the amount of assets is constant and normalized to be one in the economy. ${ }^{4}$ There is no imperfection associated with the asset market. In the overlapping generation structure all the assets sold by old consumers are bought by young investors at equilibrium.

\subsection{Temporary Equilibrium}

Let the preference of an investor be given by the linear mean variance function of future wealth

$$
U(\mu, \sigma)=\mu-\frac{\alpha}{2} \sigma^{2}
$$

where $\alpha$ is usually interpreted as a measure of risk aversion. Then, the asset demand of the young investor is given by

$$
x=\varphi\left(p, p^{e}, R^{e}, k\right):=\operatorname{Min}\left(\frac{p^{e}+\mathbb{E}[\varepsilon]-R^{e} p}{\alpha \mathbb{V}[\varepsilon]}, \frac{w(k)}{p}\right) .
$$

The price law $p=S\left(p^{e}, R^{e}, k\right)$ is implicitly defined by the solution of

$$
\varphi\left(p, p^{e}, R^{e}, k\right)=1 \text {. }
$$

\footnotetext{
${ }^{3}$ More specifically by rational expectation we mean an unbiased prediction and/or a perfect prediction whenever available.

${ }^{4}$ We do not address the issue of how firms decision to raise capital influence the economy but focus on the spill over effects of consumption decision on capital accumulation.
} 
Notice that the asset demand has an expectational lead and consumer's preferences are parameterized by the first two moments of the random variable $\varepsilon$. This means that the asset price is a deterministic function of expectations. Let $c:=\mathbb{E}[\varepsilon]-\alpha \mathbb{V}[\varepsilon]$, which can be interpreted as risk adjusted dividend payment. Then, the risk adjusted expected cum-dividend price is given by $p^{e}+c$.

Proposition 1 There exists a unique positive equilibrium price

$$
p=S\left(p^{e}, R^{e}, k\right)
$$

if the risk adjusted expected cum-dividend price is greater than zero, i.e., $p^{e}+c>0$.

The assertion in Proposition 1 is obvious as the asset demand function $\varphi\left(p, p^{e}, R^{e}, k\right)$ is decreasing in $p, \varphi\left(0, p^{e}, R^{e}, k\right)=\frac{p^{e}+\mathbb{E}[\varepsilon]}{\alpha \mathbb{V}[\varepsilon]}$ and $\lim _{p \rightarrow \infty} \varphi\left(p, p^{e}, R^{e}, k\right)=-\infty$.

Note that in equilibrium there is no short sale in the asset market as the young consumers are homogeneous. We assume that the capital investment is reversible. This means that depreciated capital is paid back as a part of the return on capital investment. Then, the capital investment, which is defined by wage minus purchases of assets gives the evolution of capital

$$
k_{1}=w(k)-p
$$

Equations (4) and (5) define the temporary equilibrium and the evolution of capital formation given expectations.

\subsection{Expectations}

Given equation (5) for capital accumulation, the return on capital at $t=1$ is given by

$$
R_{1}=R(k, p):=f^{\prime}(w(k)-p)+1-\delta .
$$

The perfect foresight at $t=0$ for the return on capital at $t=1$ requires

$$
R^{e}=R(k, p)
$$

Substituting equation (7) into equation (4), the perfect predictor $p^{e}=\Psi\left(p_{-1}^{e}, k\right)$ at $t=0$ for the asset price in $t=1$, which is consistent with a perfect prediction for the return on capital, is implicitly defined by the solution of

$$
p_{-1}^{e}=S\left(p^{e}, R(k, p), k\right) \text {. }
$$


The following proposition defines the existence of such perfect predictor. Note that given the perfect foresight for the return on capital, the asset demand now becomes dependent on wage income in general. This implies that the price law also depends on wage income in general.

Proposition 2 Let $\mathcal{D}:=\left\{\left(p_{-1}^{e}, k\right) \mid p_{-1}^{e} \in[0, w(k)), k \in \mathbb{R}_{+}\right\}$.

1. There exists a unique perfect predictor for the asset price consistent with the perfect forecasting rule in the capital market given by

$$
\Psi: \mathcal{D} \rightarrow \mathbb{R},\left(p_{-1}^{e}, k\right) \mapsto p_{-1}^{e}\left(f^{\prime}\left(w(k)-p_{-1}^{e}\right)+1-\delta\right)-c
$$

if and only if $p_{-1}^{e} \in(0, w(k))$.

2. The perfect predictor is positive if $c \leq 0$ or if $c>0$ and $p_{-1}^{e} \in(h(k), w(k))$ where $h(k)$ is implicitly defined by $\Psi(h(k), R(k, h(k)), k)=0$.

See the appendix for a proof.

Proposition 2 defines a subset $\mathcal{P}(k) \subset \mathbb{R}_{+}$for all $k \in \mathbb{R}_{+}$, such that for all $p_{-1}^{e} \in \mathcal{P}(k)$ there exists a positive perfect predictor for the next period's asset price which is given by

$$
\mathcal{P}(k):= \begin{cases}p_{-1}^{e} \in(0, w(k)) & \text { if } c \leq 0 \\ p_{-1}^{e} \in(h(k), w(k)) & \text { if } c>0 .\end{cases}
$$

Given the perfect predictor $\Psi$, there exists an equivalent price map along which a perfect point prediction is guaranteed. Then, the dynamical system for the closed economy under rational expectations is given by

$$
\begin{aligned}
& k_{1}=G(p, k):=w(k)-p \\
& p_{1}=\Psi(p, k):=p\left(f^{\prime}(w(k)-p)+1-\delta\right)-c .
\end{aligned}
$$

\section{Dynamics of the Closed Economy}

The dynamical system for the closed economy under rational expectations is defined by (10). It was shown in Section 3.2 that the perfect asset price predictor is not defined when the budget constraint is binding. Even when the budget constraint is not binding, the 
perfect predictor can be negative if $c>0$. This is a general feature of the CAPM models for a given positive return on riskless assets as in Böhm, Deutscher \& Wenzelburger (2000) and Böhm \& Chiarella (2005). Since the dynamical system is only defined for a subset of $\mathbb{R}_{+}^{2}$, the question arises whether there exists a forward invariant set of the system. To investigate the existence of steady states under rational expectation and their stability properties we have to specify the production function. For a Cobb-Douglas production function Kikuchi (2006) shows that multiple steady states may exist however all the steady states are unstable. This means that we do not obtain a forward invariant set of the dynamical system under rational expectation unless the economy is in a steady state initially or on a saddle path. In order to allow for a full dynamic analysis of the closed economy, let the production function be of the following quadratic form

$$
f(k)= \begin{cases}A k(2 d-k) & \text { if } k<d \\ A d^{2} & \text { if } k \geq d .\end{cases}
$$

Figure 1 illustrates the quadratic production function with the associated wage function.

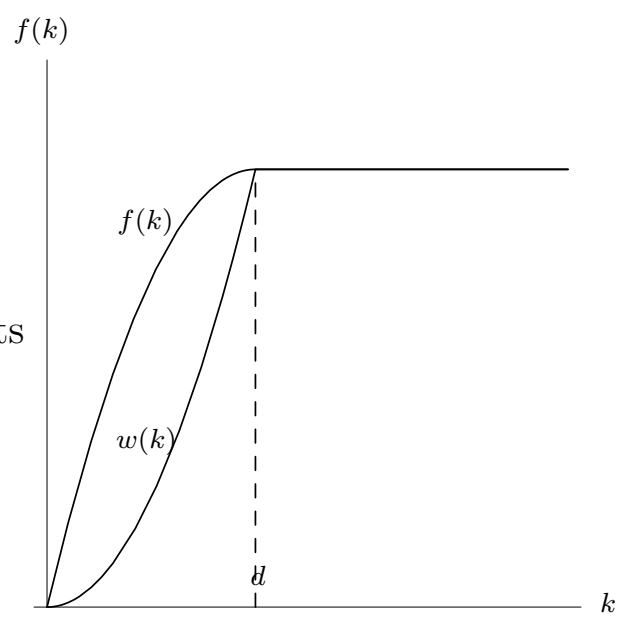

Figure 1: Quadratic Production Function

This quadratic production function has a technically convenient property that the first derivative is a linear function. ${ }^{5}$ Notice that the first derivative of the quadratic function violates one of the Inada conditions since $\lim _{k \rightarrow 0}=2 A d$. This properties have a decisive influence on the existence and stability properties of the dynamical system since the wage function is not globally concave. The following proposition characterizes the existence and the stability property of all steady states.

\footnotetext{
${ }^{5}$ Day (1983) was one of the first to exploit the property of this function.
} 
Proposition 3 Let the production function be given by equation (11).

a) If $c>0$, there exist at most two steady states. Both of them are positive, unstable and $k<d$.

b) If $c \leq 0$, there exist two positive steady states if and only if $\left(A d^{2}-d\right) \delta>-c$. One is unstable and $k<d$. The other is stable and $k \geq d$.

See the appendix for a proof.

Proposition 3 shows that there exists a stable steady state with the quadratic production function under certain conditions. Let the steady states be defined by the zero of the following functions

$$
\left(\begin{array}{c}
\Delta p(p, k) \\
\Delta k(p, k)
\end{array}\right):=\left(\begin{array}{l}
p-\Psi(p, k) \\
k-G(p, k)
\end{array}\right) .
$$

Figure 2 shows the zero contour of the functions $\Delta p(p, k)$ and $\Delta k(p, k)$ given by

$$
p= \begin{cases}\left(\begin{array}{c}
-\frac{c}{\delta-2 A(d-k)} \\
A k^{2}-k
\end{array}\right) & \text { if } k<d \\
\left(\begin{array}{c}
-\frac{c}{\delta} \\
A d^{2}-k
\end{array}\right) & \text { if } k \geq d .\end{cases}
$$

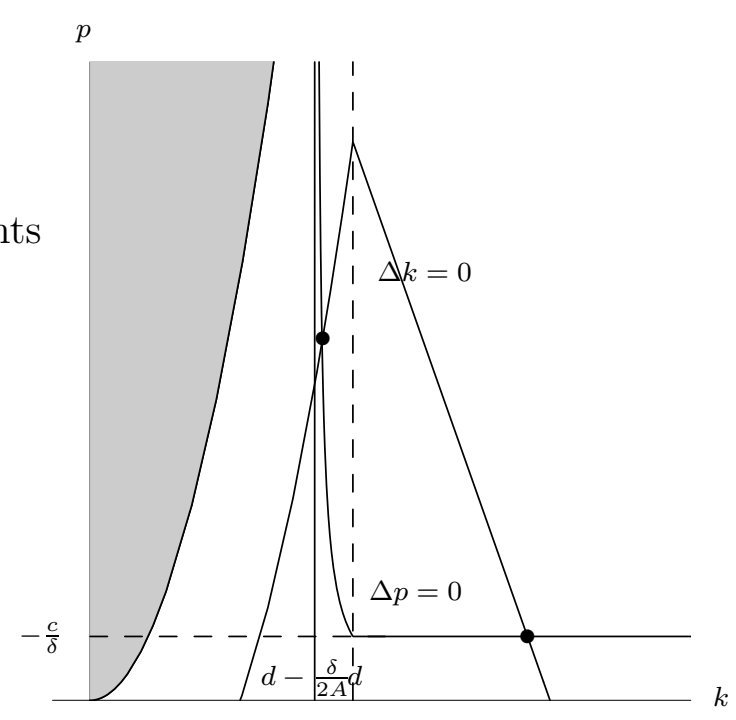

Figure 2: Phase diagram for the closed economy: $c<0$

The steady states are given by the intersections of $\Delta p(p, k)=0$ and $\Delta k(p, k)=0$. The gray shaded area is defined by $p>w(k)$ and depicts the area where the budget 
constraint is binding. Remember from Proposition 2 that the perfect predictor $\Psi$ is only defined on $p \in(0, w(k))$ for $c \leq 0$. It can be confirmed from the figure that there exists a forward invariant set of the dynamical system (10) around the stable steady state $(p, k)=\left(-\frac{c}{\delta}, A d^{2}+\frac{c}{\delta}\right)$.

\section{$5 \quad$ Two country model}

In this section we assume that the world economy consists of two countries inhabited by homogeneous consumers. The production technologies in both countries are assumed to be identical making the two countries distinguished only by the initial capital stock. The asset markets of the two countries are integrated into an international market, while there exist capital markets in both countries. We assume that when young consumers buy assets in the international market, they do not distinguish between assets of the two countries. We also assume that consumers cannot invest in the capital market abroad. In other words, we rule out foreign direct investment. Therefore, agents affect the capital stock in the foreign country only through the international asset market. Since young agents can be shareholders of the foreign firm, capital investment is now dependent on foreign asset demand unlike in the closed economy where young agents buy all available assets in the market. In turn, the asset demand is dependent on wage income, which generates a feedback effect between capital stocks in both countries. Moreover, different wage incomes in both countries enable short selling in equilibrium of the international asset market. In such an equilibrium, the international asset market serves as an international credit market inducing trading of consumption commodities across countries.

\subsection{Temporary Equilibrium in the International Asset Market}

Suppose that there exist international assets composed of assets in the two countries which pay a dividend ${ }^{6}$ of

$$
d=\frac{\varepsilon^{1}+\varepsilon^{2}}{2}
$$

Since the productivity shocks in two countries are both i.i.d. random variables drawn

\footnotetext{
${ }^{6}$ The random variable $d$ should not be confused with the parameter $d$ of the quadratic production function. In what follows the random variable $d$ will appear only as $\mathbb{E}[d]$ and $\mathbb{V}[d]$.
} 
from the same distribution, the first and second moment of $d$ will be

$$
\mathbb{E}[d]=\mathbb{E}\left[\frac{\varepsilon^{1}+\varepsilon^{2}}{2}\right]=\mathbb{E}\left[\varepsilon^{1}\right]=\mathbb{E}\left[\varepsilon^{2}\right]
$$

and

$$
\mathbb{V}[d]=\mathbb{V}\left[\frac{\varepsilon^{1}+\varepsilon^{2}}{2}\right]=\frac{1}{2} \mathbb{V}\left[\varepsilon^{1}\right]=\frac{1}{2} \mathbb{V}\left[\varepsilon^{2}\right]
$$

respectively. If we assume rational expectations for the future dividend as before, we obtain the asset demand function of young consumers at $t=0$ given $\mathrm{by}^{7}$

$$
x^{i}=\varphi\left(p, p^{e}, R^{i e}, k^{i}\right):=\operatorname{Min}\left(\frac{p^{e}+\mathbb{E}[d]-R^{i e} p}{\alpha \mathbb{V}[d]}, \frac{w\left(k^{i}\right)}{p}\right), \text { for } i=1,2 .
$$

The price law $p=S\left(p^{e}, R^{1 e}, R^{2 e}, k^{1}, k^{2}\right)$ is implicitly defined by the solution of

$$
\varphi\left(p, p^{e}, R^{1 e}, k^{1}\right)+\varphi\left(p, p^{e}, R^{2 e}, k^{2}\right)=2 .
$$

Proposition 4 There exists a unique positive equilibrium price

$$
p=S\left(p^{e}, R^{1 e}, R^{2 e}, k^{1}, k^{2}\right)
$$

if the risk adjusted expected cum-dividend price is greater than zero, i.e., $p^{e}+c>0$.

The assertion in Proposition 4 is obvious as the asset demand function $\varphi\left(p, p^{e}, R^{e}, k\right)$ is decreasing in $p, \varphi\left(0, p^{e}, R^{e}, k\right)=\frac{p^{e}+\mathbb{E}[\varepsilon]}{\alpha \mathbb{V}[\varepsilon]}$ and $\lim _{p \rightarrow \infty} \varphi\left(p, p^{e}, R^{e}, k\right)=-\infty$.

In the overlapping generations structure, all assets in the market are purchased by young agents in the economy. In the two country model available assets in the market are purchased by young agents in both countries. Therefore, the amount of assets purchased by young agents in one country is no longer equal to the available assets in the market as it was the case in the closed economy model. Therefore, the next period capital in each country $i=1,2$ is now dependent on the asset demand in each country and is given by

$$
k_{1}^{i}=w\left(k^{i}\right)-\varphi\left(p, p^{e}, R^{i e}, k^{i}\right) p .
$$

\footnotetext{
${ }^{7}$ For ease of notation we suppress the superscript $i=1,2$ denoting the individual country whenever we only focus on the mathematical properties.
} 


\subsection{Expectations and Dynamical System}

To describe the complete dynamical system we have to define how the young agents form their expectations. Let us first define the perfect predictor on the returns on capital $R_{1}^{i}$ for $i=1,2$ and then we will see under what condition there exists a perfect predictor for the next period asset price $p_{1}$, which is consistent with the perfect foresight on $R_{1}^{i}$. The return on capital in $t=1$ in each country $i=1,2$ is given by

$$
R_{1}^{i}=R\left(k^{i}, \varphi\left(p, p^{e}, R^{i e}, k^{i}\right), p\right):=f^{\prime}\left(w\left(k^{i}\right)-\varphi\left(p, p^{e}, R^{i e}, k^{i}\right) p\right)+1-\delta .
$$

The perfect foresight for the returns on capital requires that $R_{1}^{i}=R^{i e}$, which is equivalent to

$$
R^{i e}=f^{\prime}\left(w\left(k^{i}\right)-\varphi\left(p, p^{e}, R^{i e}, k^{i}\right) p\right)+1-\delta
$$

Notice that the perfect predictor $R^{i e}=\mathcal{R}\left(k^{i}, p^{e}, p\right)$ is only implicitly defined by the solution of equation (22). The following lemma proves the existence.

Lemma 1 Suppose that $\left(k^{i}, p^{e}, p\right) \in \mathbb{R}_{+}^{3}$ and Assumptions 1 and 2 are satisfied.

1. There exists a unique perfect predictor $R^{i e}=\mathcal{R}\left(k^{i}, p^{e}, p\right)$ which solves the equation (22).

2. Given the perfect predictor $\mathcal{R}$, we always obtain an interior asset demand, i.e., $\varphi\left(p, p^{e}, R^{i e}, k^{i}\right)<\frac{w\left(k^{i}\right)}{p}$.

Lemma 1 ensures an interior equilibrium in the asset market, in which young agents do not invest their entire income. This is because the return from capital investment tends to infinity as the asset demand tends to $\frac{w\left(k^{i}\right)}{p}$. Given the perfect predictor $\mathcal{R}$, we can now define the asset demand which is consistent with the perfect foresight for the returns on capital investment.

$$
\xi\left(p, k^{i}, p^{e}\right):=\varphi\left(p, p^{e}, \mathcal{R}\left(k^{i}, p^{e}, p\right), k^{i}\right)=\frac{p^{e}+\mathbb{E}[d]-\mathcal{R}\left(k^{i}, p^{e}, p\right) p}{\alpha \mathbb{V}[d]}
$$

Then, the perfect predictor predictor $\Psi\left(p, k^{1}, k^{2}\right)$, which is consistent with the perfect foresight for the return on capital investment, is defined by

$$
\xi\left(p, k^{1}, p^{e}\right)+\xi\left(p, k^{2}, p^{e}\right)=2 .
$$


Proposition 5 Let $\hat{\mathcal{D}}:=\left\{\left(p_{-1}^{e}, k^{1}, k^{2}\right) \mid p_{-1}^{e} \in\left[0, \min \left\{w\left(k^{1}\right), w\left(k^{2}\right)\right\}\right),\left(k^{1}, k^{2}\right) \in \mathbb{R}_{+}^{2}\right\}$ and Assumptions 1 and 2 be satisfied.

1. There exists a unique perfect predictor, which is consistent with the perfect foresight for the return on capital $\mathcal{R}$ given by

$$
\Psi: \hat{\mathcal{D}} \rightarrow \mathbb{R},\left(p_{-1}^{e}, k^{1}, k^{2}\right) \mapsto \Psi\left(p_{-1}^{e}, k^{1}, k^{2}\right)
$$

2. The perfect predictor is positive if and only if $\xi\left(p, k^{1}, 0\right)+\xi\left(p, k^{2}, 0\right)<2$.

Given the existence of the perfect predictors $(\Psi, \mathcal{R})$ the dynamical system of the two country model under rational expectations is characterized by

$$
\begin{aligned}
& k_{1}^{1}=\Phi\left(k^{1}, k^{2}, p\right):=w\left(k^{1}\right)-p\left(1-\frac{\mathcal{R}\left(k^{1}, \Psi\left(p, k^{1}, k^{2}\right), p\right)-\mathcal{R}\left(k^{2}, \Psi\left(p, k^{1}, k^{2}\right), p\right)}{2 \alpha \mathbb{V}[d]} \cdot p\right) \\
& k_{1}^{2}=\Phi\left(k^{2}, k^{1}, p\right):=w\left(k^{2}\right)-p\left(1-\frac{\mathcal{R}\left(k^{2}, \Psi\left(p, k^{1}, k^{2}\right), p\right)-\mathcal{R}\left(k^{1}, \Psi\left(p, k^{1}, k^{2}\right), p\right)}{2 \alpha \mathbb{V}[d]} \cdot p\right) \\
& p_{1}=\Psi\left(p, k^{1}, k^{2}\right):=\frac{\mathcal{R}\left(k^{1}, \Psi\left(p, k^{1}, k^{2}\right), p\right)+\mathcal{R}\left(k^{2}, \Psi\left(p, k^{1}, k^{2}\right), p\right)}{2} \cdot p-c .
\end{aligned}
$$

The dynamical system (26) shows the link between the international asset market and the capital accumulation in each country.

Suppose that $k^{1}>k^{2}$, then $\mathcal{R}\left(k^{1}, \Psi\left(p, k^{1}, k^{2}\right), p\right)<\mathcal{R}\left(k^{2}, \Psi\left(p, k^{1}, k^{2}\right), p\right)$. This implies that the investment of country 1 in international mutual funds is greater than 1 and the investment of country 2 is less than 1 . This means that country 1 accumulates less capital than country 2 inducing a convergence force.

Proposition 6 There exists positive symmetric steady states under rational expectations which coincide with the positive steady states of the closed economy.

The proof follows directly from the dynamical system (26).

\section{Dynamics of the Two Country Model}

Section 5.2 showed that the perfect predictor for the asset price is only defined on a subset of $\mathbb{R}_{+}$. The question arises whether there exists a forward invariant set of the dynamical system (26). Section 4 showed that the dynamical system of the closed economy has 
a forward invariant set if we use the quadratic production function. Moreover, it was shown that the stable steady state is unique in the closed economy. To compare our results of the two country model with those of the closed economy model, we use the quadratic production function to investigate the existence and the stability properties of steady states under rational expectations. The linearity of the first derivative of the quadratic function is essential to obtain a closed form solution of the model. However, the violation of one of the Inada conditions has a consequence on the model structure. Remember that the asset demand was never constrained by income in Section 5. This was because the return on capital investment tends to infinity as agents invest more and more in the asset market. This result rests on the assumption that $\lim _{k \rightarrow 0} f^{\prime}(k)=\infty$. Without this assumption, we need to consider all three cases 1) the budget constraints are binding in both countries, 2) the budget constraint is binding only in one country, 3) the budget constraints are not binding in either countries. The derivation of the asset demand function $\varphi$ and the perfect predictors $(\Psi, \mathcal{R})$ can be found in Kikuchi $(2006)$.

\subsection{Multiple Steady States}

From Proposition 6 we know that the symmetric steady state of the two country model is identical to the steady state of the closed economy model. Therefore, the existence of the symmetric steady state is already characterized by Proposition 3. The following proposition gives the condition when the two countries convergence to the symmetric steady state.

\section{Proposition 7}

1. There exists a positive symmetric steady state $k^{1}=k^{2}=A d^{2}+\frac{c}{\delta}$ if $c \leq 0$ and $\delta\left(A d^{2}-d\right)>-c$.

2. If $k^{1}=k^{2}$ or $k^{1}, k^{2}>d$, the two countries converge to this symmetric steady state for initial values in its neighborhood.

See the appendix for a proof.

Proposition 7 states two conditions for which the two countries converge to the symmetric steady state. If the two countries have identical initial conditions, there are no financial flows between them and the economy follows the path of the closed economy. If the two countries have initial capital stocks which exceed the critical value $d$, they 
will have an identical law of accumulation. Therefore, the dynamics becomes that of the closed economy.

Definition 1 We call an asymmetric steady state an interior steady state if the budget constraints are not binding for the asset demand in either rich and poor country and if there are financial flows between two countries.

Proposition 8 There exists an interior asymmetric steady state in which $k^{2}<d<k^{1}$ and $x^{2}<0<x^{1}$.

See the appendix for a proof.

Proposition 8 implies that $w\left(k^{1}\right)>I\left(k^{1}\right)>I\left(k^{2}\right)>w\left(k^{2}\right)$ at the asymmetric steady state where $I\left(k^{i}\right):=w\left(k^{i}\right)-p x^{i}, \forall i=1,2$ denotes the capital investment in each country. This means that the poor country requires external finance from the rich country in form of short selling in the international asset market for its capital investment. More generally, the asset demand of the poor country is always lower than that of the rich country since the asset demand function is increasing in $k$.

\subsection{Nonconvergence and Inequality of Nations}

To analyze the stability properties of all the steady states we rely on numerical simulation in this section. The quadratic production function is used throughout the numerical analysis. To obtain rational expectations for the next period dividend, the following assumption is made about the random variable $d$.

Assumption 5 We assume that the random variable $\varepsilon$ has a uniform distribution on the interval $[a, b]$. The probability density function for a continuous uniform distribution on the interval $[a, b]$ is

$$
P(\varepsilon)= \begin{cases}0 & \text { if } d<a \\ \frac{1}{b-a} & \text { if } a \leq d \leq b \\ 0 & \text { if } d>b\end{cases}
$$

with mean $\frac{a+b}{2}$ and variance $\frac{(b-a)^{2}}{12}$.

The standard parameter set in Table 1 will be used unless it is otherwise indicated. 


\begin{tabular}{|c|c|c|c|c|c|c|c|c|}
\hline$A$ & $d$ & $\mathbb{E}[d]$ & $\mathbb{V}[d]$ & $\alpha$ & $c$ & $k_{0}^{1}$ & $k_{0}^{2}$ & $p_{0}$ \\
\hline 0.5 & 3.2 & 0.5 & 0.25 & 1 & 0.25 & 3 & 1 & 0.4 \\
\hline
\end{tabular}

Table 1: Standard parameter set

To analyze the sensitivity of the dynamical system with respect to initial conditions Figure 3 shows the typical basin of attraction for the asymmetric steady states for a negative and a positive $c$. The cyan red color depicts initial conditions for which two countries converge to the respective asymmetric steady state and the white color those for which the dynamical system explodes.

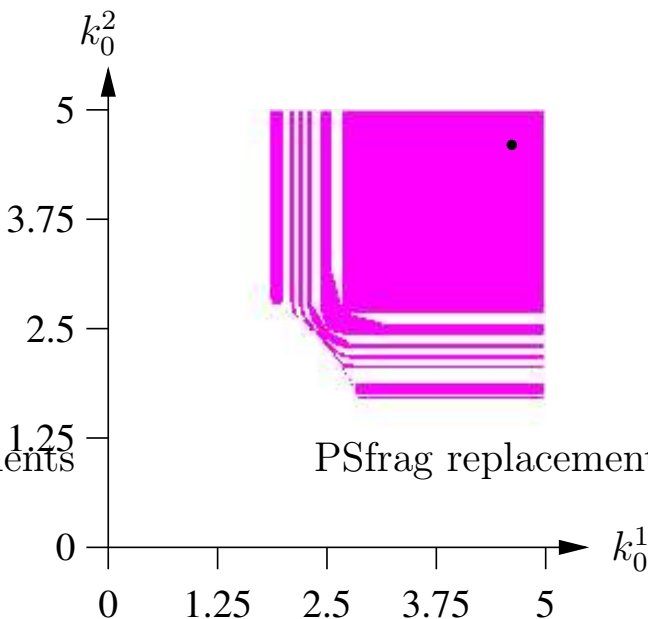

(a) $c=-0.15$

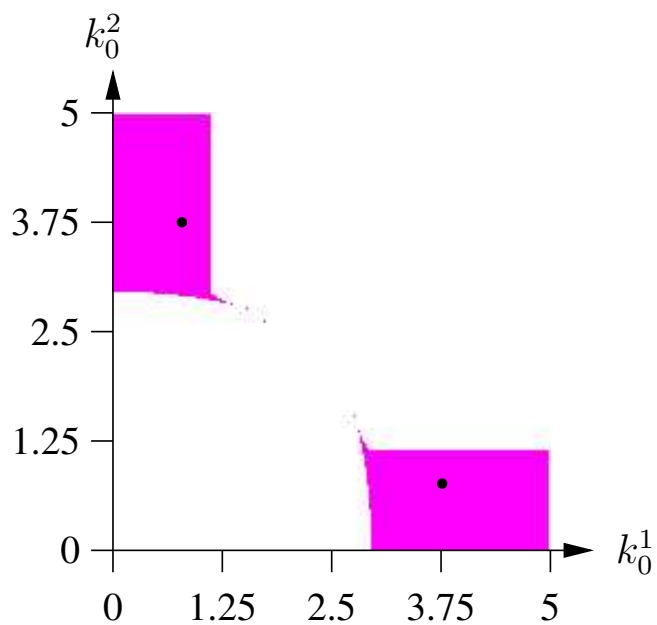

(b) $c=0.25$

Figure 3: Basin of attraction for the asymmetric steady states: $\delta=0.625$

Figure 3 shows that the asymmetric steady state $k^{1}<d<k^{2}$ described in Proposition 8 is stable for $c>0 .{ }^{8}$ The stability of the interior steady state suggests that unconstrained optimal behavior at individual level under rational expectations does not necessarily lead to convergence of income between the two countries even in absence of any imperfections in the markets. We know from Proposition 7 that there exists no positive symmetric steady state where $k>d$ if $c>0$ and the steady state of the closed economy is stable only if $k>d$ and $c<0$. Even in the two country model this stability property seems to hold. This means that the feedback mechanism between the capital stocks of the two countries through the asset price does not alter the stability properties of the steady

\footnotetext{
${ }^{8}$ The numerical simulation shows that there exists an open parameter set for which this interior steady state is stable.
} 
states of the closed economy. In particular, the steady states of the closed economy where $k<d$ remain unstable. Moreover, Figure 3 suggests that stable asymmetric steady states do not coexist with a stable symmetric steady state. Put it differently, this suggests that the risk adjusted expected dividend $c$ plays a crucial role on whether we observe convergence or divergence of the two countries. To summarize we observe that there exists a forward invariant set of dynamical system (26) which is consistent with rational expectations where initially poor and rich countries diverge if $c>0$ and converge if $c \leq 0$. This statement should be treated with caveat. Especially, it does not mean that whether the two countries converge or diverge depends on $c$. Notice that there is no overlap of the basins of attraction for a positive and a negative $c$. Whether we obtain a forward invariant set depends on the initial conditions in each case. Only if the initial conditions of the two countries are sufficiently high and the risk adjusted dividend is negative, the two countries converge to each other. If the initial condition of one country is sufficiently low and that of the other sufficiently high, the two countries diverge in the long run.

Let us look at how the risk adjusted dividend $c$ influences the equilibrium price. The equilibrium price in the steady state of the closed economy is negative for $c>0$ and $k>d$ since

$$
p=-\frac{c}{\delta-f^{\prime}(k)}
$$

where $f^{\prime}(k)=0$ if $k>d$. This is not necessarily the case in the two country case since the equilibrium price is dependent on the return on capital investment in both countries so that

$$
p=-\frac{2 c}{2 \delta-f^{\prime}\left(k^{1}\right)-f^{\prime}\left(k^{2}\right)} .
$$

Notice that even if $k^{1}>d$ and therefore $f^{\prime}\left(k^{1}\right)=0$, the equilibrium price is not necessarily negative for $c>0$ if $k^{2}<d$. This is in particular the case at the asymmetric interior steady state.

On the other hand, a positive steady state to exist for a negative $c$,

$$
f^{\prime}\left(k^{1}\right)+f^{\prime}\left(k^{2}\right)<2 \delta .
$$

This means that both countries need to have high capital stock. For a positive $c$, Figure 3 shows that the two countries converge to a symmetric steady state if the initial conditions of the two countries are sufficiently high. The following proposition states the implication of the asymmetric steady state for the inequality of the two countries. 
Proposition 9 Suppose that $A d>1$. The poor country is better off while the rich country is worse off at the interior steady state than in the steady sate without an asset market.

Proof: Suppose that $k^{2}<k^{1}$. From Proposition 8, we know $x^{1}>0>x^{2}$ at the interior asymmetric steady state. The capital accumulation laws in both poor and rich countries at the asymmetric steady state are given by

$$
\begin{aligned}
& k^{1}=A d^{2}-p x^{1} \\
& k^{2}=A\left(k^{2}\right)^{2}-p x^{2} .
\end{aligned}
$$

Equations (28) and (29) imply that $0<k^{2}<k^{1}<A d^{2}$. Suppose that there exists no asset market. Then the evolution of capital in the economy is given by

$$
k_{1}=w(k)= \begin{cases}A k^{2} & \text { if } k<d \\ A d^{2} & \text { if } k \geq d\end{cases}
$$

If $A d>1$, the economy without an asset market has three steady states, $0,1 / A$, and $A d^{2}$. The steady state $1 / A$ is unstable since the function $w(k)$ cuts the 45 degree line from below. Hence, the economy with $k_{0}<\frac{1}{A}$ converges to zero while the economy with $k_{0}>\frac{1}{A}$ converges to $A d^{2}$.

Let us examine the result of Proposition 9 by comparing equations (28), (29), and (30). Figure 4 depicts the map (28) by the horizontal green line, the map (29) by the green curve, and the map (30) by the blue curve.

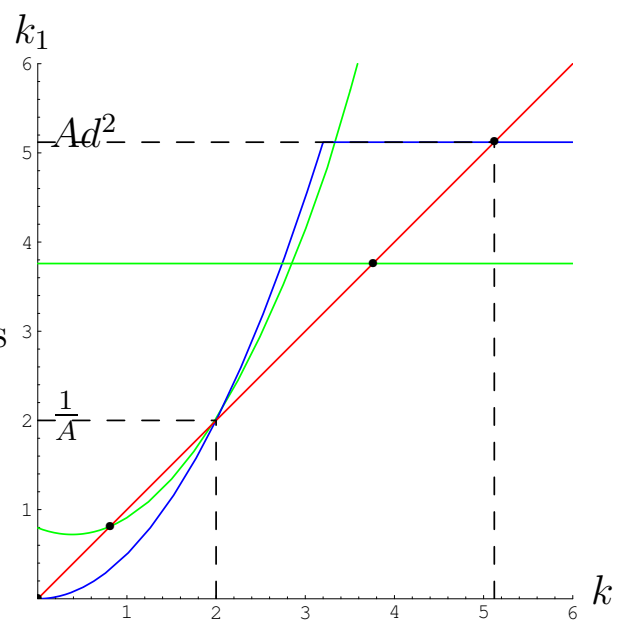

Figure 4: Time one maps given steady state asset demands: $\alpha=1$. 
Figure 4 shows that the high steady state of the economy without an asset market $k=A d^{2}$ shifts down while the low steady state 0 shifts up. The mechanism behind Proposition 9 is build on two aspects of the model. Firstly, the map (29) has a positive intercept at $k^{2}=0$ because $x^{2}<0$. Secondly, the multiple steady states arise from the convexity of the wage function in the map (29). On one hand, the poor country takes credits to invest capital in domestic production through short selling of assets in the international asset market, which constitutes an equalizing force. On the other hand, the non concavity of the wage function induces an unequalizing force since the initial difference in capital stocks between two countries leads to an even larger difference in their wages. The interaction of these two mechanisms supports the existence and the stability of the interior asymmetric steady state.

\subsection{Endogenous Fluctuations of International Capital Flows}

Figure 5 shows a bifurcation diagram with respect to the depreciation rate $\delta$ displaying the limiting behavior of both state variables $k^{1}$ and $k^{2}$.

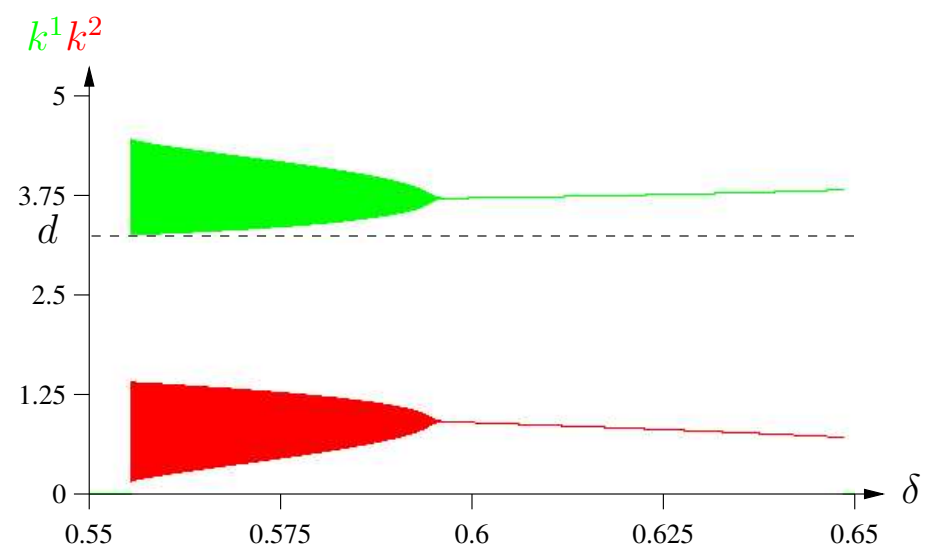

Figure 5: Bifurcation diagram

The figure confirms the existence of the stable asymmetric steady state where $k^{2}<$ $d<k^{1}$. One can observe that as the depreciation rate $\delta$ decreases, the steady state undergoes a bifurcation. The following proposition characterizes the bifurcation.

Proposition 10 The interior asymmetric steady state $k^{2}<d<k^{1}$ undergoes a supercritical Neimark-Sacker bifurcation.

See the appendix for a proof. 
Figure 6 (a) shows a closed invariant curve which appears after the bifurcation point and Figure 6 (b) shows the corresponding time series. Figure 5 shows that the invariant curve around $k^{1}$ touches $d$ if we further decrease $\delta$. This means that the dynamical system switches from the case where $k^{2}<d<k^{1}$ to the case where $k^{1}, k^{2}<d$. We observe that when the $k^{1}$ touches $d$, the invariant curve becomes unstable.

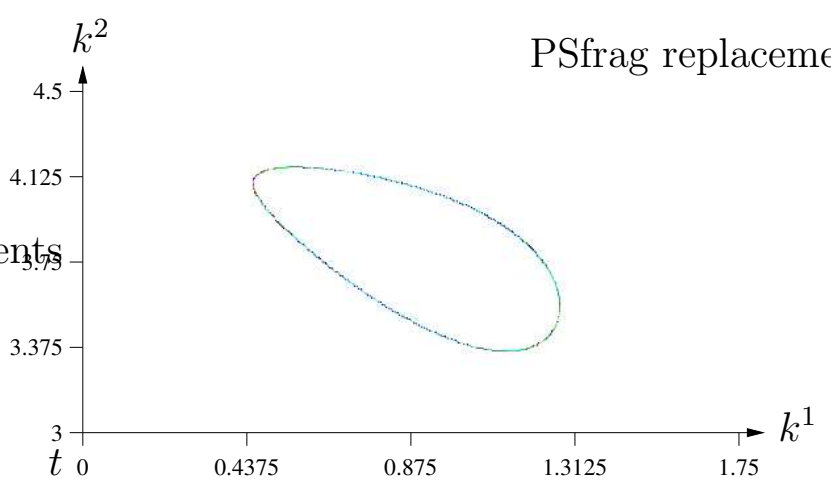

(a) A closed invariant curve

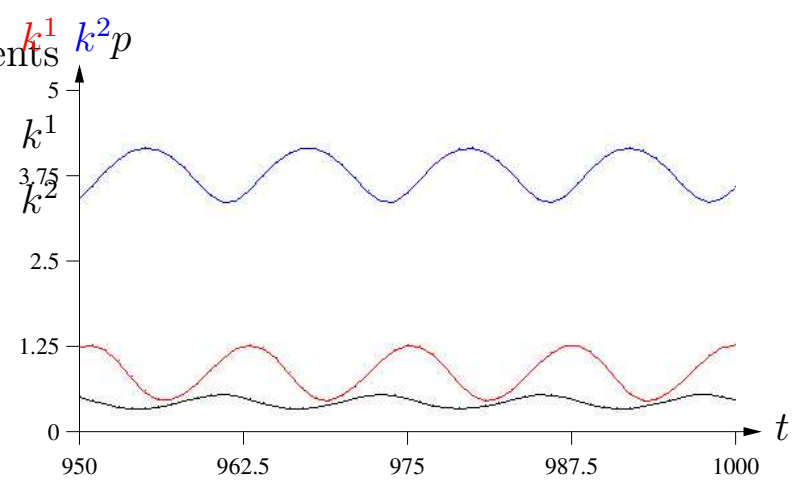

(b) Time Series

Figure 6: Endogenous fluctuations: $\delta=0.575$

The closed economy model did not generate endogenous fluctuations. This suggests that the interaction between the two economies generates endogenous fluctuations in capital flows between the rich and the poor country. This result can be taken as an evidence that fluctuations observed in international financial markets may occur under rational expectations even in absence of any exogenous shocks or imperfections in the economy.

\section{Concluding Remarks}

The conventional view of the implications of an international asset market in the presence of uncertainty is rather simple. With access to a larger market, countries can better diversify their risks and be engaged in more efficient production. The two underlining aspects of this view is that 1) a larger market provides better opportunity for risk diversification 2) more risky projects are more productive. While we also kept the first aspect in our model, we diverted from the second aspect. We assumed that there exist nominal assets which are not productive but can be traded in the market. The firms pay the stochastic profit as dividends and the young consumers choose optimal portfolio to transfer their wealth over time. Since young agents in both countries have different income in general, short selling is possible in the international asset market. In 
other words, trade of assets takes place between generations as well as across countries. Capital flows from rich to poor countries because the international asset market is more attractive to agents in the rich country where the rate of return in the domestic capital market is relatively low. However, the model showed that the optimal behavior at the individual level does not necessarily lead to convergence of incomes between the two countries. This result should be treated with caveat. It is wrong to conclude that the asset market is responsible for the divergence. We made a rather restrictive assumption that the asset market is the only market which allows for transactions between the two countries. This allowed us to fucus on a particular aspect of the asset market that trading is subject to price expectations. The model showed that the associated risk in the asset market plays a decisive role on whether convergence or divergence prevails depending on the initial conditions of the two countries.

The result on divergence can be contrasted to the findings in Boyd \& Smith (1997) and Matsuyama (2004). The asymmetric steady states do not emerge due to an enforcement problem in the financial market. In contrast, they arise due to the availability of trading of an additional unproductive asset without any imperfection in the market. While consumers in the poor country in Boyd \& Smith (1997) and Matsuyama (2004) face a borrowing constraint, they hold an optimal portfolio, which is an interior solution in the present paper. This induces capital flows from the rich to the poor country while the capital flows are reversed at the asymmetric steady state in the financial market with imperfections. The capital flows from the rich to the poor country is empirically more plausible. The deviation of the result in the present paper from that in Boyd \& Smith (1997) and Matsuyama (2004) has different implications for the inequality of nations. While the poor country, trading with the rich country, is worse off in terms of income per capita in models with financial imperfections, the relationship is reversed in the present model with an additional asset market. The result on endogenous fluctuation offers a new insight into the nature of the integrated economies. Financial market globalization may be accompanied by increasing volatility of the market and by periodic and cyclical reoccurrence of financial crisis without any exogenous shocks. This provides an additional explanation to phenomena which can not be fully understood by a propagation mechanism of exogenous shocks. 


\section{Appendix}

\section{Proof of Proposition2}

Fist we show that the perfect predictor $\Psi$ is well defined if the budget constraint is not binding. Let $G\left(p^{e}, k, p\right):=\varphi\left(p, p^{e}, R(k, p), k\right)-1$. By the implicit function theorem, we obtain that $\frac{\partial}{\partial p_{-1}^{e}} \Psi(p, k)=-\frac{G_{p}}{G_{p}} . \quad G_{p}<0$ and $G_{p^{e}}>0$ if $\varphi\left(p, p^{e}, R(k, p), k\right)=$ $\frac{p^{e}+\mathbb{E}[\varepsilon]-R(k, p) p}{\alpha \mathbb{V}[\varepsilon]}$. If $\varphi\left(p, p^{e}, R(k, p), k\right)>\frac{w(k)}{p}, p=w(k)$ and $G_{p^{e}}=0$. This shows that the perfect predictor $\Psi$ is not defined if the budget constraint is binding. Furthermore, $\Psi(0, k)=-c$. This implies that if $c>0$, the perfect predictor $\Psi$ is negative for $p \in(0, h(k))$.

\section{Proof of Proposition 3}

We prove the existence and stability of all positive steady states. We examine the case where 1) $k \geq d$ and then 2) $k<d$.

1) For $k \geq d$, the steady state is defined by

$$
\begin{aligned}
& p=-\frac{c}{\delta} \\
& p=A d^{2}-k .
\end{aligned}
$$

This excludes any positive steady states $(p, k)$ where $k>d$ and $p>0$ for $c>0$. If $c \leq 0$, there exists a unique positive steady state $(p, k)$, if $A d^{2}-d>-\frac{c}{\delta}$. The system in the neighborhood of the steady state is given by

$$
\begin{aligned}
& p_{1}=(1-\delta) p-c \\
& k_{1}=A d^{2}-p .
\end{aligned}
$$

The Jacobian is

$$
J(p, k)=\left(\begin{array}{cc}
1-\delta & 0 \\
-1 & 0
\end{array}\right) .
$$

The determinant is zero and the trace is $1-\delta$. The eigenvalues are 0 and $1-\delta$. Thus the steady state where $k>d$ is stable.

2) For $k<d$, the steady state is defined by

$$
\begin{aligned}
& p=p(2 A(d-k)+1-\delta)-c \\
& p=A k^{2}-k .
\end{aligned}
$$


The system in the neighborhood of the steady state is given by

$$
\begin{aligned}
& p_{1}=p\left(f^{\prime}\left(A k^{2}-p\right)+1-\delta\right)-c \\
& k_{1}=A k^{2}-p .
\end{aligned}
$$

Figure 7 shows there exist at most two steady states if $c>0$ and there exists always one steady state if $c \leq 0$ and $\delta\left(A d^{2}-d\right)>-c$.

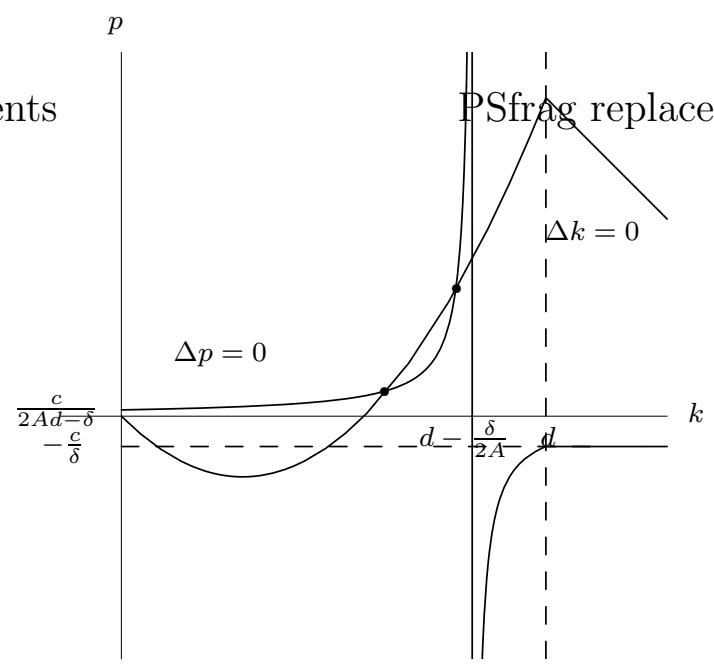

(a) $c>0$

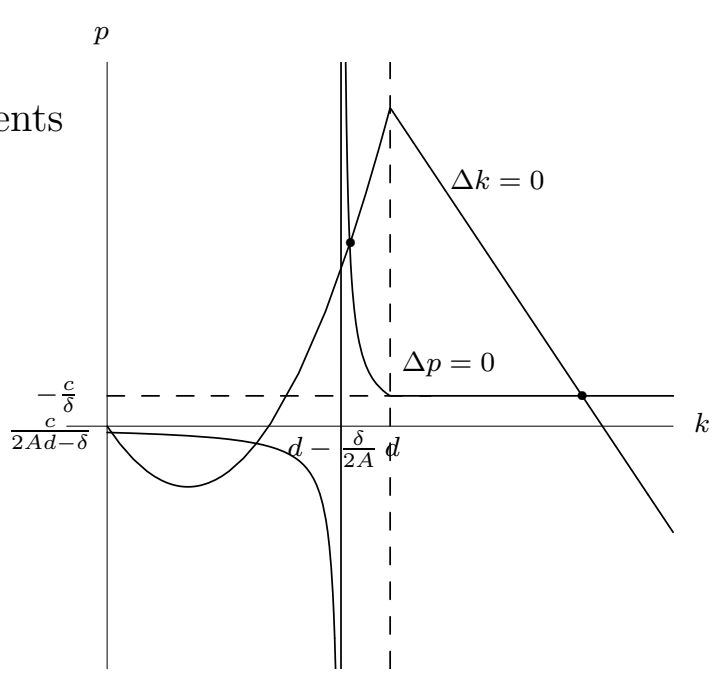

(b) $c \leq 0$

Figure 7: Phase diagram for the closed economy

The Jacobian is

$$
J(p, k)=\left(\begin{array}{cc}
2 A(d-k+p)+1-\delta & -4 A^{2} p k \\
-1 & 2 A k
\end{array}\right) .
$$

The determinant is $4 A^{2} k(d-k)+2 A k(1-\delta)>0$ and the trace is $2 A(d+p)+1-\delta>0$. Substituting equation (37), the trace can be rewritten as $2 A(d-k)+2 A^{2} k^{2}+1-\delta$. From equation (37) we know that at positive steady states $A k>1$. Thus, the trace is always greater than 2 at any positive steady states. Hence, all the steady states where $k<d$ are unstable.

\section{Proof of Lemma 1}

The left hand side of the equation (22) is the identity. The right hand side is a decreasing function in $R^{i e}$ since $\frac{\partial}{\partial R^{i e}} \varphi\left(p, p^{e}, R^{i e}, k^{i}\right)<0$ and $\lim _{R^{i e} \rightarrow \infty} f^{\prime}\left(w\left(k^{i}\right)-\varphi\left(p, p^{e}, R^{i e}, k^{i}\right) p\right)+$ 
$1-\delta=1-\delta$. In addition, $f^{\prime}\left(w\left(k^{i}\right)-\varphi\left(p, p^{e}, 0, k^{i}\right) p\right)+1-\delta>0$. This proves the unique existence. Given the perfect predictor $\mathcal{R}$, the perfect foresight for returns on capital $R^{i e}$ tends to infinity as the asset demand tends to $\frac{w\left(k^{i}\right)}{p}$. The utility function, which is increasing in future wealth, guarantees that the young agent will not invest the entire income in the asset market.

\section{Proof of Proposition 5}

The prefect predictor is defined by equation (24). The right hand side is a positive constant. We show that the left hand side is an increasing function in $p^{e}$, which ensures a unique solution. To start with, let us examine the properties of the function $\xi$.

$$
\frac{\partial}{\partial p^{e}} \xi(p, k, \cdot)=\frac{1}{\alpha \mathbb{V}[d]}\left(1-\frac{\partial}{\partial p^{e}} \mathcal{R}(k, \cdot, p)\right)
$$

This means that $\frac{\partial}{\partial p^{e}} \xi(p, k, \cdot)>0$ is equivalent to $\frac{\partial}{p^{e}} \mathcal{R}(k, \cdot, p) p<1$. From equation (22), let $G\left(R^{e}, p^{e}, k, p\right):=R^{e}-f^{\prime}\left(w(k)-\varphi\left(p, p^{e}, R^{e}, k\right) p\right)-1+\delta$. By the implicit function theorem,

$$
\frac{\partial}{\partial p^{e}} \mathcal{R}(k, \cdot, p)=-\frac{\frac{\partial}{\partial p^{e}} G\left(R^{e}, \cdot, k, p\right)}{\frac{\partial}{\partial R^{e}} G\left(\cdot, p^{e}, k, p\right)}=-\frac{f^{\prime \prime}\left(w(k)-\varphi\left(p, p^{e}, R^{i e}, k^{i}\right) p\right) \frac{p}{\alpha \mathbb{V}[d]}}{1-f^{\prime \prime}\left(w(k)-\varphi\left(p, p^{e}, R^{i e}, k^{i}\right) p\right) \frac{p^{2}}{\alpha \mathbb{V}[d]}} .
$$

Hence, $\frac{\partial}{\partial p^{e}} \mathcal{R}(k, \cdot, p) p<1$ implies that $0<1$. Therefore, $\frac{\partial}{\partial p^{e}} \xi(p, k, \cdot)>0$. This ensures a unique solution $p^{e}=\Psi\left(p, k^{1}, k^{2}\right)$ defined by the solution of equation (24). If $\xi$ is increasing in $p^{e}$ and $\xi\left(p, k^{1}, 0\right)+\xi\left(p, k^{2}, 0\right)>2$, the solution $p^{e}$ is obviously negative.

\section{Proof of Proposition 7}

We show that the two countries have an identical law of accumulation if $k^{1}=k^{2}<d$ or $k^{1}, k^{2} \geq d$. Then, the dynamics follows that of the closed economy. If $k^{1}=k^{2}<d$, the dynamical system reduces to a two dimensional system given by

$$
\begin{aligned}
& k_{1}=A k^{2}-p \\
& p_{1}=f^{\prime}\left(A k^{2}-p\right) p+(1-\delta) p-c .
\end{aligned}
$$

If $k^{1}, k^{2} \geq d$, the dynamical system reduces to a two dimensional system given by

$$
\begin{aligned}
& k_{1}=A d^{2}-p \\
& p_{1}=(1-\delta) p-c .
\end{aligned}
$$


From Proposition 3 we know that there exists the stable steady state $A d^{2}-\frac{c}{\delta}$ if and only if $c \leq 0$ and $\delta\left(A d^{2}-d\right)>-c$.

\section{Proof of Proposition 8}

Suppose that $k^{2}<d<k^{1}$ in steady state. Then the steady state is defined by

$$
\begin{aligned}
k^{1} & =A d^{2}-p\left(1+\frac{p A\left(d-k^{2}\right)}{\alpha \mathbb{V}[d]}\right) \\
k^{2} & =A\left(k^{2}\right)^{2}-p\left(1-\frac{p A\left(d-k^{2}\right)}{\alpha \mathbb{V}[d]}\right) \\
p & =p\left(A\left(d-k^{2}\right)+1-\delta\right)-c
\end{aligned}
$$

First we show the existence of the steady state for $c>0$ and $A d>\delta$. Then, we show that in the steady state, $x^{2}<0<x^{1}$, i.e., the poor country sells assets short while the rich country demands a positive number.

Equations (43) and (44) can be rewritten as

$$
\begin{aligned}
k^{2} & =d-\frac{\delta}{A}-\frac{c}{A p} \\
k^{2} & =\frac{\alpha \mathbb{V}[d]+p^{2} A}{2 A \alpha \mathbb{V}[d]} \pm \sqrt{\left(\frac{\alpha \mathbb{V}[d]+p^{2} A}{2 A \alpha \mathbb{V}[d]}\right)^{2}+\frac{p(\alpha \mathbb{V}[d]-p A d)}{A \alpha \mathbb{V}[d]}}
\end{aligned}
$$

Substituting equation (44) into (42) we obtain

$$
k^{1}=A d^{2}-p\left(1+\frac{c}{\alpha \mathbb{V}[d]}+\frac{p \delta}{\alpha \mathbb{V}[d]}\right)
$$

Figure 8 shows the sets defined by equations (45), (46), and (47) for $c>0$ and $A d>\delta$ where the intersections of sets defined by equations (45) and (46) depict the steady state values for $k^{2}$ and $p$. The corresponding steady state value of $k^{1}$ is depicted on the set defined by equation (46). Notice that for the steady state value $\bar{p}$, there exist corresponding steady state values for $k^{1}$ and $k^{2}$ where $k^{2}<d<k^{1}$.

Now we prove that $x^{2}<0<x^{1}$ in the steady state by contradiction. Notice that in the steady state in Figure 8,

$$
\frac{\alpha \mathbb{V}[d]}{A d}<\frac{c}{A d-\delta}
$$

Suppose that $x^{2}>0$ in the steady state. From equation (43) this means that

$$
1-\frac{p \delta+c}{\alpha \mathbb{V}[d]}>0 \Longrightarrow p<\frac{\alpha \mathbb{V}[d]-c}{\delta} .
$$




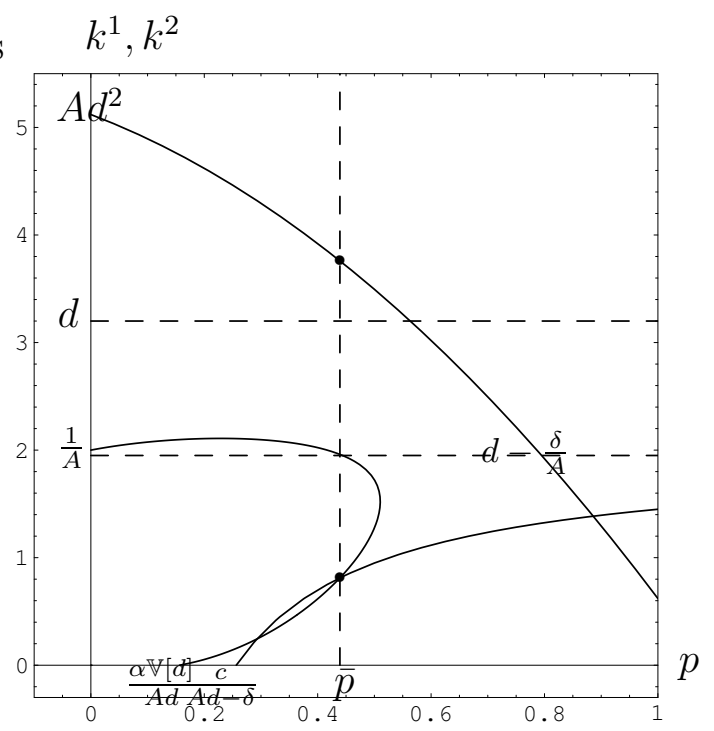

Figure 8: Existence of asymmetric steady states

From Figure 8 a necessary condition for the steady state is that

$$
p>\frac{c}{A d-\delta} .
$$

This means that $\frac{\alpha \mathbb{V}[d]-c}{\delta}>\frac{c}{A d-\delta}$ has to hold so that $x^{2}>0$ in the steady state, which is equivalent to

$$
\frac{\alpha \mathbb{V}[d]}{A d}>\frac{c}{A d-\delta}
$$

This is a contradiction. Hence, $x^{2}<0$ in the steady state. Since $p\left(x^{1}+x^{2}\right)=2$ in any steady state, $x^{2}<0<x^{1}$ follows.

\section{Proof of Proposition 10}

The dynamical system in the neighborhood of the steady state where $k^{2}<d<k^{1}$ is defined by

$$
\begin{aligned}
& k_{1}^{1}=\Phi^{1}\left(k^{1}, k^{2}, p\right)=A d^{2}-p\left(1-\frac{p\left((1-\delta)-R^{2}\left(k^{1}, k^{2}, p\right)\right)}{2 \alpha \mathbb{V}[d]}\right) \\
& k_{1}^{2}=\Phi^{2}\left(k^{1}, k^{2}, p\right)=A\left(k^{2}\right)^{2}-p\left(1-\frac{p\left(R^{2}\left(k^{1}, k^{2}, p\right)-(1-\delta)\right)}{2 \alpha \mathbb{V}[d]}\right) \\
& p_{1}=\tilde{\Psi}\left(p, k^{1}, k^{2}\right)=\frac{p}{2}\left(1-\delta+R^{2}\left(k^{1}, k^{2}, p\right)\right)-c .
\end{aligned}
$$

where $R^{2}\left(k^{1}, k^{2}, p\right)=\frac{\alpha \mathbb{V}[d]\left(2 A\left(d-A\left(k^{2}\right)^{2}+p+\frac{p^{2}(1-\delta)}{2 \alpha \mathbb{V}[d]}\right)+(1-\delta)\right)}{\alpha \mathbb{V}[d]+A p^{2}}$. 
The Jacobian matrix of the dynamical system is

$$
J\left(\bar{k}^{1}, \bar{k}^{2}, p\right)=\left(\begin{array}{ccc}
\frac{\partial \Phi^{1}(\cdot)}{\partial k^{1}} & \frac{\partial \Phi^{1}(\cdot)}{\partial k^{2}} & \frac{\partial \Phi^{1}(\cdot)}{\partial p} \\
\frac{\partial \Phi^{2}(\cdot)}{\partial k^{1}} & \frac{\partial \Phi^{2}(\cdot)}{\partial k^{2}} & \frac{\partial \Phi^{2}(\cdot)}{\partial p} \\
\frac{\partial \Psi(\cdot)}{\partial k^{1}} & \frac{\partial \Psi(\cdot)}{\partial k^{2}} & \frac{\partial \Psi(\cdot)}{\partial p}
\end{array}\right) .
$$

Since the first column of the above matrix has only zero entry, we can consider the sub-matrix

$$
\left(\begin{array}{cc}
\frac{\partial \Phi^{2}(\cdot)}{\partial k^{2}} & \frac{\partial \Phi^{2}(\cdot)}{\partial p} \\
\frac{\partial \Psi(\cdot)}{\partial k^{2}} & \frac{\partial \Psi(\cdot)}{\partial p}
\end{array}\right)=\left(\begin{array}{cc}
2 A k^{2}+\frac{p^{2}}{2 \alpha \mathbb{V}[d]} \frac{\partial R^{2}(\cdot)}{\partial k^{2}} & \frac{p\left(R^{2}(\cdot)-(1-\delta)\right)}{\alpha \mathbb{V}[d]}-\bar{x}+\frac{p^{2}}{2 \alpha \mathbb{V}[d]} \frac{\partial R^{2}(\cdot)}{\partial p} \\
\frac{p}{2} \frac{\partial R^{2}(\cdot)}{\partial k^{2}} & \frac{1-\delta+R^{2}(\cdot)}{2}+\frac{p}{2} \frac{\partial R^{2}(\cdot)}{\partial p}
\end{array}\right) .
$$

The determinant and the trace of the above $2 \times 2$ matrix is

$$
\begin{gathered}
\operatorname{det}=\frac{2 A^{2} k^{2}\left(d-A\left(k^{2}\right)^{2}+p\right) \alpha^{2} \mathbb{V}[d]^{4}}{\left(A p^{2}+\alpha \mathbb{V}[d]\right)^{2}}+\frac{2 A k^{2} \alpha \mathbb{V}[d](1-\delta)}{A p^{2}+\alpha \mathbb{V}[d]} \\
\operatorname{tr}=A \alpha \mathbb{V}[d]\left(\frac{A^{2}\left(k^{2}\right)^{2} p^{2}+\left(d+2\left(k^{2}+p\right)\right) \alpha \mathbb{V}[d]}{\left(A\left(p^{e}\right)^{2}+\alpha \mathbb{V}[d]\right)^{2}}-\frac{A\left(d p^{2}+k^{2}\left(-2 p^{2}+k^{2} \alpha \mathbb{V}[d]\right)\right.}{\left(A p^{2}+\alpha \mathbb{V}[d]\right)^{2}}\right) \\
+\frac{(1-\delta)\left(\alpha^{2} \mathbb{V}[d]^{4}+2 A \alpha \mathbb{V}[d] p^{2}+A^{2} p^{2}\right)}{\left(A p^{2}+\alpha \mathbb{V}[d]\right)^{2}}
\end{gathered}
$$

The points (a), (b) and (c) in Figure 9 corresponds to $\delta=(0.625,0.594719,0.575)$ in Figure 5. As the value of $\delta$ decreases from 0.625 to 0.575 the determinant crosses 1 at $\delta=0.594719$ which proofs that the system goes through a Neimark Sacker bifurcation.

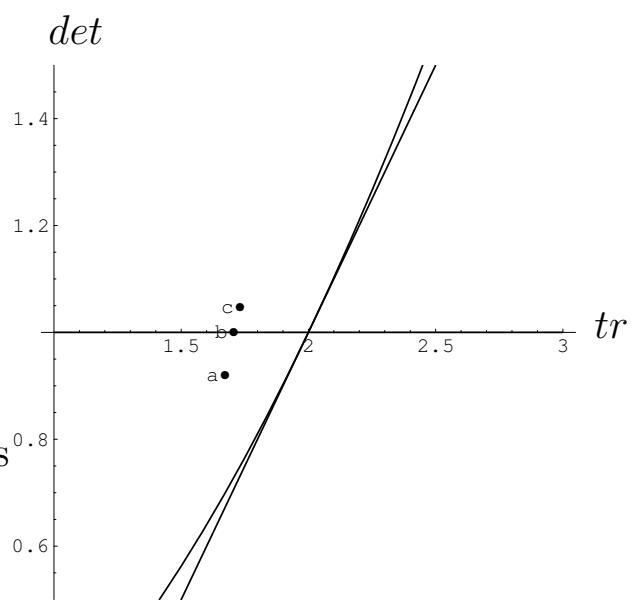

Figure 9: Stability triangle: $\delta=(0.625,0.594719,0.575)$ 


\section{References}

Acemoglu, D., \& Zilibotti, F. (1997): "Was Prometheus Unbounded by Chance? Risk, Diversification and Growth", Journal of Political Economy, (105), 709-751.

Boyd, J. H., AND B.D. Smith (1997): "Capital Market Imperfections, International Credit Markets, and Nonconvergence", Journal of Economic Theory,(73), 335-364.

Böhm, V., And Chiarella, C. (2005): "Mean Variance Preferences, Expectations Formations, and the Dynamics of Random Asset Prices", Mathematical Finance, (15), 61-98 .

Böhm, V., Deutscher, N., And Wenzelburger, J. (2000): "Endogenous Random Asset Prices in Overlapping Generations Economies", Mathematical Finance, (10), 23-38.

Böhm, V. And J. Wenzelburger (2002): "Perfect Predictions in Economic Dynamical Systems with Random Perturbations", Macroeconomic Dynamics, 6, 687-712.

DAY, H. R. (1983): "The Emergence of Chaos from Classical Economic Growth", Quarterly Journal of Economics, (98), 201-213.

Donaldson, J. B., \& Mehra, R. (1984): "Comparative Dynamics of an Equilibrium Intertemporal Asset Pricing Model", Review of Economic Studies, (51), 491-508.

Galor, O. (1996): "Convergence? Inferences from Theoretical Models", Economic Journal, (106), 1056-1069.

Goldsmith, R. W. (1969): Financial Sturcture and Development, Yale University Press.

Huffman, G.(1986): "Asset Pricing with Capital Accumulation" International Economic Review, (27), 565-582.

Kikuchi, T. (2006): Inequality of Nations, Endogenous Fluctuations, and Financial Market Globalization, Ph.D. dissertation, Department of Economics, Bielefeld University.

Lucas, R. E. JR. (1990): "Why Doesn't Capital Flow from Rich to Poor Countries?", American Economic Review, 80, 92-96. 
Matsuyama, K. (2004): "Financial Market Globalization, Symmetry-Breaking, and Endogenous Inequality of Nations", Econometrica, 72, 853-884.

Obstfeld, M. (1994):"Risk-Taking, Global Diversification, and Growth", American Economic Review, (84), 1310-1329.

Romer, P. M. (1990): "Endogenous Technological Change", Journal of Political Economy, (98), 71-102. 